\title{
Brain activation in non-human primate pain model using functional MRI
}

\author{
Hiroki Ushirozako ', Go Yoshida ', Tomohiko Hasegawa ', Yu Yamato ${ }^{2}$, \\ Takahiro Natsume ${ }^{3}$, Shinya Ogawa ${ }^{3}$, Yuji Awaga ${ }^{3}$, Aldric Hama ${ }^{3}$, \\ Hiroyuki Takamatsu ${ }^{3}$, and Yukihiro Matsuyama ${ }^{1}$ \\ ${ }^{1}$ Department of Orthopedic Surgery, Hamamatsu University School of Medicine \\ ${ }^{2}$ Department of Orthopedic Surgery and Division of Geriatric Musculoskeletal Health, \\ Hamamatsu University School of Medicine \\ ${ }^{3}$ Pharmacology Group, Hamamatsu Pharma Research, Inc.
}

\begin{abstract}
Functional magnetic resonance imaging (fMRI) is expected as a biomarker of pain because it can objectively evaluate changes in cerebral blood flow associated with neuron activity against pain. We have developed pain models for cynomolgus macaques because it is more compatible with humans in regard to the structures and functions of brain regions which is suggested to be involved in pain in humans. Aside from humans, the cynomolgus macaques are the most widespread primate genus, ranging from Japan to North Africa. Since the macaques are the animal species closest to humans among those which can be used for invasive experiments, they are widely used to understand the mechanisms of the human brain. The purpose of this study is to elucidate pain-related brain activation regions in the macaque models using fMRI. Generally, pain testing in animal models has been based on avoidance behavior against pain stimuli. However, we identified painrelated brain activation regions using fMRI under propofol anesthesia as a more objective evaluation method. In the macaque model of chymopapain-induced discogenic low back pain, the activity of the insular cortex occurred in response to lumbar compression stimulation. In the macaque model of oxaliplatin-induced neuropathic cold hypersensitivity, activation of the insular cortex also occurred in response to cold stimuli. As a result of evaluating pregabalin, duloxetine and tramadol, only duloxetine showed behavioral effectiveness and suppressed activation of the insular cortex due to oxaliplatin-induced neuropathic pain. In the macaque model of postoperative pain, activation of the insula cortex was mainly activated by pressure stimulation. As a result of evaluating morphine, pregabalin and diclofenac, only morphine showed behavioral effectiveness and suppressed activation of the insular cortex due to postoperative pain. However, macaques with naturally occurring endometriosis exhibited a pain response against pressure stimuli to the abdomen, and had activation of the thalamus. As a result of evaluat-
\end{abstract}


ing morphine, meloxicam and acetaminophen, only morphine showed behavioral effectiveness and suppressed activation of thalamus due to abdominal pain from endometriosis. It was suggested that the brain activation regions could change due to various conditions that can cause the pain, as the acute pain increased activation in the insula cortex and the chronic pain increased activation in the thalamus. This study demonstrated the usefulness of fMRI as a pain biomarker, and fMRI analysis using the macaques might provide an advantage for the translation of the findings to human patients. Therefore, these study will contribute to the development of new analgesics for each pain as well as to the progress in the areas of brain research.

Keywords

Thalamus; Insula cortex; Nonhuman primate; Brain activation;

Functional magnetic resonance imaging

Received: 11 November 2019

\title{
Functional MRI を用いたカニクイザル疼痛誘発モデルにおける痛みの可視化
}

\author{
後迫 宏紀 ${ }^{1} /$ 吉田 剛 $1 /$ 長谷川 智彦 $1 /$ 大和 雄 $2 /$ 夏目 貴弘 $3 /$ 小川 真弥 3

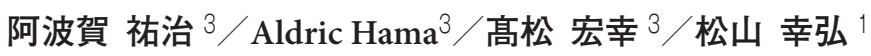 \\ 1 浜松医科大学 整形外科学講座 \\ ${ }^{2}$ 浜松医科大学 長寿運動器疾患教育研究講座 \\ ${ }^{3}$ 株式会社 浜松ファーマリサーチ
}

\section{はじめに}

近年, 画像診断装置の技術進歩にともない, MRI 装置を用いて非侵襲的かつ造影剤などを必 要とせずに, functional MRI (fMRI) や局所脳血 流イメージングなどが容易に実施できるように なり, 疼痛患者の脳機能評価について様々な知 見が報告されている 1,6,8)。fMRI は痛みに対す る脳神経活動に伴う脳血流変化を客観的に評価 できるため, 痛みのバイオマーカーとして期待 されている 5,13)。我々と共同研究を行っている 浜松ファーマリサーチは, ヒトと生体力学性お よび脳領域の役割が近いカニクイザルを用いた 疼痛モデルの開発を行っており, そのモデルの
一つとして椎間板障害による腰痛が脳のどの領 域を賦活するか fMRI を用いて評価した ${ }^{14)}$ 。過 去に腰痛以外にもカニクイザルを用いた変形性 膝関節モデル 9,10)，オキサリプラチン誘発末梢 神経障害モデル 7,12), 術後痛モデル 3 , 子宮内 膜症モデル 15) など様々な痛みを有する病態モデ ルを開発し，その痛みを行動評価および fMRI にて評価し報告した。これらの研究を通して, 各種痛みを誘発する病態によって賦活される脳 領域に差異がある可能性が明らかになってきた。

高齢化社会を迎え, 何らかの痛みを有する患 者は増加の一途にあり, 中でも腰痛に苦しむ患 者の数は非常に多く, さらに様々な原因によっ て生じるため, 痛みによって賦活化される脳領 
域は様々である ${ }^{4,6)}$ 。我々は，まず腰痛の原因の 一つとして考えられている椎間板障害性腰痛と 脳賦活化部位の関係について，カニクイザルを 用いて明らかにした。本稿では主に椎間板障害 性疼痛モデルの作成および脳賦活化部位の特徴 を述べ，その他疼痛動物モデルを用いた研究か ら得られた知見と比較し報告する。

\section{カニクイザルを用いた 椎間板障害性疼痛モデルの確立}

腰痛は我が国において最多の主訴であり，平 成 28 年度国民生活基礎調査の有訴者率は人口 千人当たり 104.1 であり，日常診療の現場で多 くの患者に遭遇する（http://www.e-stat.go.jp/ SG1/estat/NewList.do?tid=000001031016)。腰痛 患者の中には明らかな器質的異常がなく，心理 的・社会的要因や認知・情動障害など脳機能異 常が関連する症例がある。近年，さまざまな原 因にて生じる慢性腰痛の脳機能変化を明らかに するために，fMRIを用いた基礎研究が行われ ている 1,6,8)

腰痛のバイオマーカーとして使用できる可能 性のある fMRI は，1 人の患者に繰り返し行え る点で，患者の治療方針決定や治療評価に最適 なモダリティーといえる15)。しかし，fMRI は 個人レベルでの差がでるほどの精度がないため に痛みの評価として臨床で使用される機会が少 ない。その理由の一つとして，ヒトは痛みと同 時に認知，情動，視覚情報などによる脳活動が 生じやすいことが挙げられる。

マウスやイヌなどの椎間板性腰痛動物モデル の問題点として，痛みの評価が困難であり，4 足歩行のために椎間板への力学的負荷がヒトと 異なることが挙げられる11)。モデル動物として は 2 足歩行可能なサルが適しており, 椎間板へ

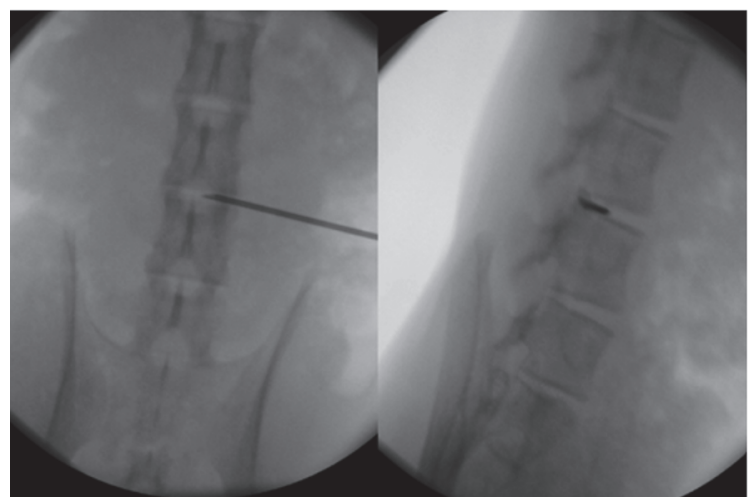

Fig.1 Fluoroscopy-guided puncture of the intervertebral disc. An 18-gauge needle attached to a syringe was percutaneously inserted into the nucleus pulposus. The tip of the needle rested in the center of the nucleus pulposus.

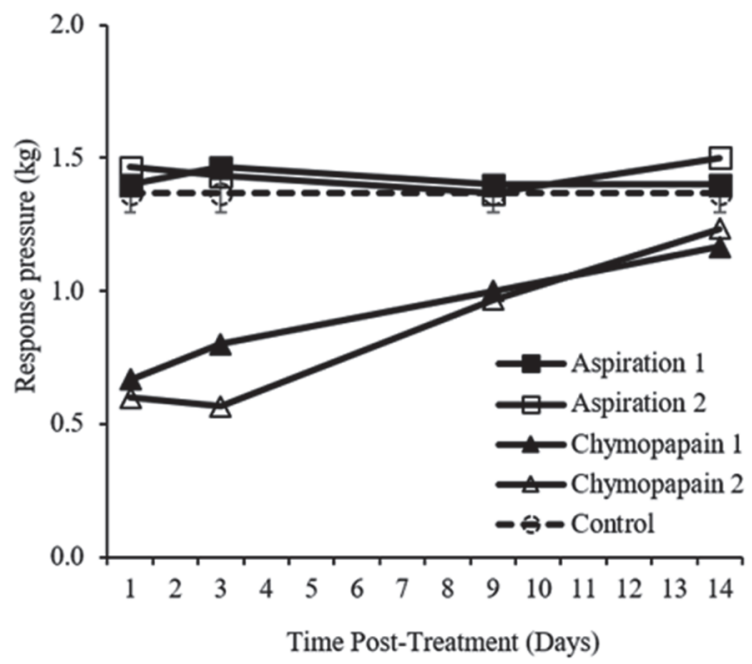

Fig.2 Pressure sensitivity of the lumbar back following chymopapain treatment. Response pressure thresholds $(\mathrm{kg})$ were measured over time after either chymopapain treatment or aspiration of the intervertebral disc. Pressure thresholds of untreated ("control") macaques are expressed as mean \pm standard deviation (modified from Ref. 14).

の力学的負荷がヒトと類似している。その他の 動物モデルと同様に, 痛みの評価は困難である が，脳の形態がヒトと類似しているため，サル とヒトとの fMRI の比較が可能であり 2)，研究 素材として最も適している。 


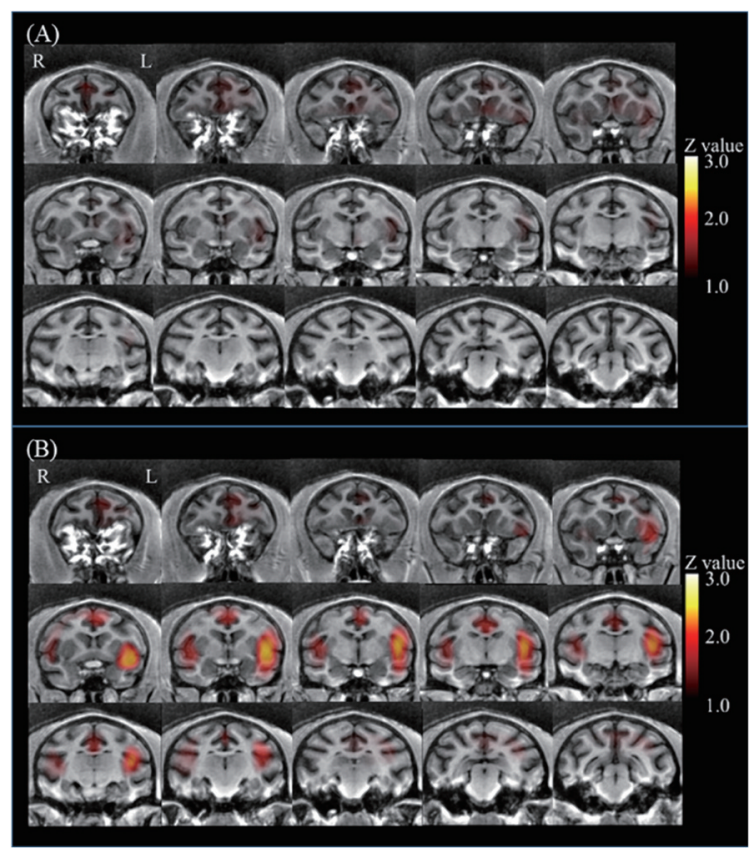

Fig.3 Coronal brain sections arranged from rostral (upper left) to caudal (lower right). Before treatment, there was no significant pressure-induced activation (A). One day after treatment, bilateral pressure-induced activation of the secondary somatosensory cortex and insular cortex was observed (B) (modified from Ref. 14).

以下の研究は浜松医科大学動物実験倫理委員 会の承認を受けて実施した。実験動物は 4 匹の 雄カニクイザル（全例 4 歳齢, 体重 $4 \sim 5 \mathrm{~kg}$ ) を 用い, injection 群 (透視下経皮的 L4/5 䯣核吸 引後 [Fig.1]に $1 \mathrm{mg} / \mathrm{ml}$ キモパパインを $0.3 \mathrm{ml}$ 注入 $; \mathrm{n}=2)$, aspiration 群 ( $\mathrm{L} 4 / 5$ 髄核吸引の み; $\mathrm{n}=2)$ とした。腰痛定量法として $\mathrm{L} 4 / 5$ レ ベル背部正中から右 $2 \mathrm{~cm}$ の部位にて加圧計測 装置を用い, 立位姿勢にて痛みによる表情変化 までの刺激間值（3回の平均值）を計測した。 Injection 群/aspiration 群の平均疼痛刺激間値 は，投与前 $1.4 / 1.4 \mathrm{~kg}$, 投与後 1 日 $0.6 / 1.4 \mathrm{~kg}$, 3 日 $0.7 / 1.5 \mathrm{~kg}, 7$ 日 $1.0 / 1.4 \mathrm{~kg}, 14$ 日 $1.2 / 1.5 \mathrm{~kg}$ であった (Fig.2)。キモパパイン注入後 7 日間の injection 群は, aspiration 群と比して刺激閾値

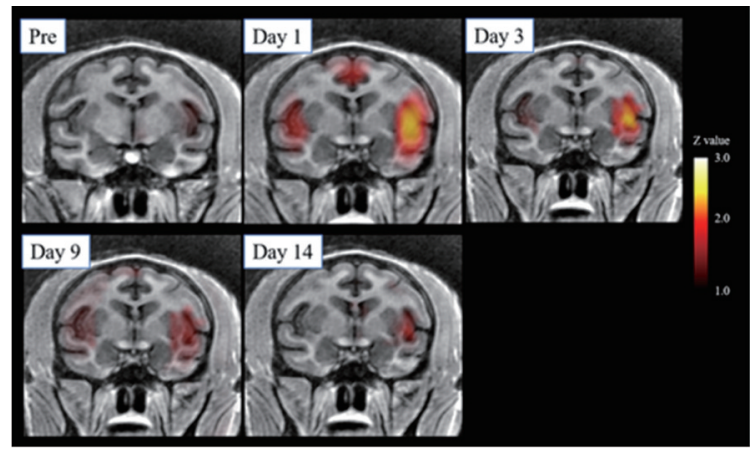

Fig.4 Low back pressure-induced brain activation over time in macaques following chymopapain treatment. Averaged brain images from two macaques treated with chymopapain. Beginning one day after chymopapain treatment, activation of the secondary somatosensory cortex and insular cortex was observed (modified from Ref. 14).

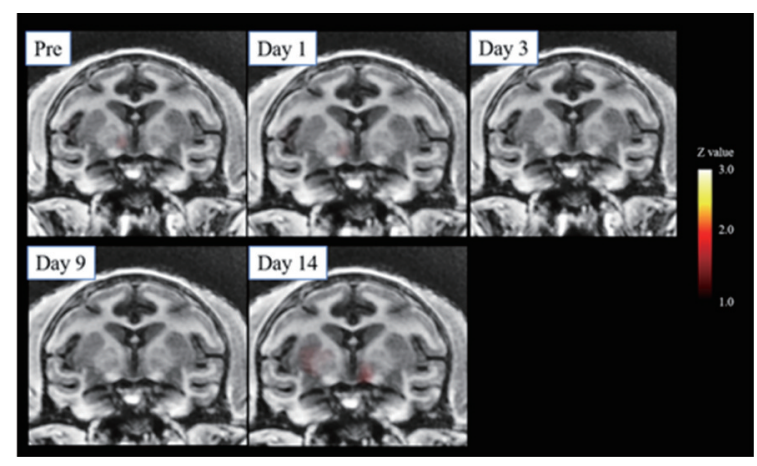

Fig.5 Lack of low back pressure-induced brain activation over time in macaques following aspiration. Averaged brain images over time from two macaques in which the nucleus pulposus was aspirated. There was a lack of significant pressure-evoked brain activation in these macaques (modified from Ref. 14).

が低く（ $p<0.05 ）$, 徐々に閾值が上昇し，投与後 14 日には差はなかった。一方, aspiration 群の 刺激閾值に変化はなかった。

\section{カニクイザル椎間板障害性疼痛モデルに おける脳活動領域の解明}

脳活動評価のため, プロポフォール鎮静下に 
Table 1 Brain activation regions of each pain model

\begin{tabular}{lccc}
\hline \multicolumn{1}{c}{ Model } & SII and Ins & ACC & Thalamus \\
\hline Oxaliplatin-induced neuropathic pain $^{7)}$ & + & - & - \\
Discogenic low back pain ${ }^{14)}$ & + & - & - \\
Postoperative pain ${ }^{3)}$ & + & + & - \\
Pain from endometriosis ${ }^{15)}$ & - & - & + \\
\hline
\end{tabular}

SII, secondary somatosensory cortex; Ins, insular cortex; ACC, anterior cingulate cortex.

fMRI（3-Testra MRI）を腹臥位にて撮影した (処置前, 処置後 $1,3,9,14$ 日)。Block-design として, 注射シリンジを用いた刺激装置を用い, 30 秒おきに痛み刺激を繰り返した。fMRI デー 夕はSPM12にて解析した。キモパパイン注入 後 3 日間の injection 群は, fMRI にて二次体性 感覚野 (SII) および島皮質 (Ins) の活動が増加 していた (Fig.3, Fig.4)。Aspiration 群の fMRI は脳活動を認めなかった (Fig.5)。椎間板性障害 性疼痛はSII および Ins の脳活動を増加させ, 疼痛刺激閾值低下と fMRI による脳活動が矛盾 しなかった。

\section{カニクイザル各種疼痛モデルの 脳活動領域の比較および鎮痛剂の薬効評価}

従来, 実験動物における疼痛試験は, 刺激に 対する回避行動が指標とされてきたが, より客 観的な評価方法として, 我々は propofol 低濃度 麻酔下での fMRI 撮影により, 痛みを感じる脳 領域の同定を行っている。

カニクイザル各種疼痛モデルの脳活動領域を

Table 1 に示す。オキサリプラチン誘発性神経 障害疼痛モデルでは冷感刺激に対して SII およ びIns の活性化が生じた7)。本モデルに対して, duloxetine, pregabalin, tramadol の有効性を 評価したところ, duloxetine のみが行動学的に
有効性を示し，SII およびInsの活性化を抑え た。椎間板障害性疼痛モデルでは, 腰部圧迫刺 激に対して，SII および Ins の活性が生じた ${ }^{14)}$ また，術後痛モデルでは圧迫刺激によって，前 帯状皮質およびSII, Ins が活性化し, morphine, pregabalin, diclofenacの有効性を評価したとこ ろ, morphine のみが行動的に有効性を示し, SII およびIns の活性化を抑えた。一方で，自 然発症の子宮内膜症サルでは, 腹部への圧刺激 に応じて疼痛反応を呈し，その他のモデルと異 なり視床が活性化していた 15)。この疼痛反応に 対し, morphine, meloxicam, acetaminophen の有效性を評価したところ, morphineのみが 行動的に有効性を示し, 視床の活性化を抑えた。 これまでの結果より，急性痛ではSII および Ins, 慢性痛では視床が活性化し, 痛みの違いに より脳の活性化部位が変化する可能性が示唆さ れた。

我々は, 疼痛モデルの作成のみでなく, 各種 鎮痛片の薬効評価を並行して行っている。これ まで新規鎮痛剂開発のための前臨床試験には, げっ歯類の疼痛モデルが使用されてきたが, げっ歯類で有効性を示した薬剤が臨床試験でそ の有用性を示せなかったケースが散見される ${ }^{9)}$ 。 痛みにおいては, げっ歯類とヒトにおいて種間 差が大きく, げっ歯類の試験結果から臨床試験 での結果を外挿することが非常に困難であるこ 
とを示している。そのため, よりヒトに近い非 ヒト霊長類での評価が必要であると考えられて きたが，疼痛領域においてヒトと非ヒト霊長類 との間にどのような相同性があるかなどの詳細 な種間比較までは国外を含めて行われていない。 したがって, 本研究の成果は脳科学領域への貢 献だけでなく，新規鎮痛剤の開発への多大な貢 献が期待できると考えている。

\section{おわりに}

本研究はカニクイザルを用いた動物実験にお ける疼痛バイオマーカーとしての fMRI の有用 性を明らかにした。疼痛領域での新薬開発には, カニクイザルを用いた fMRI 解析が有効な手段 になると考えている。今後は，本研究で開発さ れたカニクイザル腰痛モデルを用い, 腰痛を ターゲットにした新規鎮痛剂の開発を検討し， 前臨床試験の結果から臨床試験の臨床への外挿 性が高い新規薬剤評価試験が期待される。

利益相反の開示: 演題発表に関連し，開示すべき COI 関係にある企業等はなし。共著者の夏目貴 弘, 小川真弥, 阿波賀祐治, Aldric Hamaは, 本研究における共同研究契約を締結した株式会 社浜松ファーマリサーチの社員であり, 高松宏 幸は株式会社浜松ファーマリサーチの代表取締 役である。

\section{文 献}

1) Baliki, M.N., Chialvo, D.R., Geha, P.Y., Levy, R.M., Harden, R.N., Parrish, T.B., Apkarian, A.V., Chronic pain and the emotional brain: specific brain activity associated with spontaneous fluctuations of intensity of chronic back pain, J. Neurosci., 26 (2006) 12165-12173.

2) Dubowitz, D.J., Chen, D.Y., Atkinson, D.J., Scadeng, M., Martinez, A., Andersen, M.B., Andersen, R.A., Bradley, W.G. Jr., Direct comparison of visual cortex activation in human and non-human primates using functional magnetic resonance imaging, J. Neurosci. Methods, 107 (2001) 71-80.

3) Hama, A., Natsume, T., Ogawa, S., Awaga, Y., Hayashi, I., Matsuda, A., Takamatsu, H., PainRelated Behavior and Brain Activation in a Cynomolgus Macaque Model of Postoperative Pain, CNS Neurol. Disord. Drug Targets, 17 (2018) 348-360.

4) Kaneko, H., Zhang, S., Sekiguchi, M., Nikaido, T., Makita, K., Kurata, J., Konno, S., Dysfunction of Nucleus Accumbens Is Associated With Psychiatric Problems in Patients With Chronic Low Back Pain: A Functional Magnetic Resonance Imaging Study, Spine (Phila Pa 1976), 42 (2017) 844-853.

5) Kobayashi, Y., Kurata, J., Sekiguchi, M., Kokubun, M., Akaishizawa, T., Chiba, Y., Konno, S., Kikuchi, S., Augmented cerebral activation by lumbar mechanical stimulus in chronic low back pain patients: an FMRI study, Spine (Phila Pa 1976), 34 (2009) 2431-2436.

6) Kregel, J., Meeus, M., Malfliet, A., Dolphens, M., Danneels, L., Nijs, J., Cagnie, B., Structural and functional brain abnormalities in chronic low back pain: A systematic review, Semin. Arthritis Rheum., 45 (2015) 229-237.

7) Nagasaka, K., Yamanaka, K., Ogawa, S., Takamatsu, H., Higo, N., Brain activity changes in a macaque model of oxaliplatin-induced neuropathic cold hypersensitivity, Sci. Rep., 7 (2017) 4305.

8) Nakamura, Y., Nojiri, K., Yoshihara, H., Takahata, T., Honda-Takahashi, K., Kubo, S., Sakatsume, K., Kato, H., Maruta, T., Honda, T., Significant differences of brain blood flow in patients with chronic low back pain and acute low back pain detected by brain SPECT, J. Orthop. Sci., 19 (2014) 384-389.

9) Ogawa, S., Awaga, Y., Takashima, M., Hama, A., Matsuda, A., Takamatsu, H., Antinociceptive effect of clinical analgesics in a nonhuman primate model of knee osteoarthritis, Eur. J. Pharmacol., 786 (2016) 179-185.

10) Ogawa, S., Awaga, Y., Takashima, M., Hama, A., Matsuda, A., Takamatsu, H., Knee osteoarthritis pain following medial meniscectomy in the nonhuman primate, Osteoarthritis Cartilage, 24 (2016) 1190-1199.

11) Ohtori, S., Inoue, G., Miyagi, M., Takahashi, K., Pathomechanisms of discogenic low back pain in humans and animal models, Spine J., 15 (2015) 1347-1355.

12) Shidahara, Y., Ogawa, S., Nakamura, M., Nemoto, S., Awaga, Y., Takashima, M., Hama, A., Matsuda, A., Takamatsu, H., Pharmacological 
comparison of a nonhuman primate and a rat model of oxaliplatin-induced neuropathic cold hypersensitivity, Pharmacol. Res. Perspect., 4 (2016) e00216.

13) Smith, S.M., Dworkin, R.H., Turk, D.C., Baron, R., Polydefkis, M., Tracey, I., Borsook, D., Edwards, R.R., Harris, R.E., Wager, T.D., Arendt-Nielsen, L., Burke, L.B., Carr, D.B., Chappell, A., Farrar, J.T., Freeman, R., Gilron, I., Goli, V., Haeussler, J., Jensen, T., Katz, N.P., Kent, J., Kopecky, E.A., Lee, D.A., Maixner, W., Markman, J.D., McArthur, J.C., McDermott, M.P., Parvathenani, L., Raja, S.N., Rappaport, B.A., Rice, A.S.C., Rowbotham, M.C., Tobias, J.K., Wasan, A.D., Witter, J., The Potential Role of Sensory Testing, Skin Biopsy, and Functional Brain Imaging as Biomarkers in Chronic Pain Clinical Trials: IMMPACT Considerations, J. Pain, 18 (2017) 757-777.

14) Ushirozako, H., Yoshida, G., Togawa, D., Omura, T., Hasegawa, T., Yamato, Y., Banno, T., Arima, H., Oe, S., Mihara, Y., Yamada, T., Natsume, T.,
Ogawa, S., Awaga, Y., Takamatsu, H., Matsuyama, Y., Brain activation in a cynomolgus macaque model of chymopapain-induced discogenic low back pain: a preliminary study, Spine Surg. Relat. Res., 3 (2019) 368-376.

15) Yano, M., Matsuda, A., Natsume, T., Ogawa, S., Awaga, Y., Hayashi, I., Hama, A., Takamatsu, H., Pain-related behavior and brain activation in cynomolgus macaques with naturally occurring endometriosis, Hum. Reprod., 34 (2018) 469478.

Address for correspondence: Hiroki Ushirozako Department of Orthopedic Surgery, Hamamatsu University School of Medicine 1-20-1 Handayama, Hamamatsu, Shizuoka 431-3192, Japan

※ 本稿は第 41 回日本疼痛学会 (2019 年 7 月, 名古 屋)「公募シンポジウム 2 : 痛みの定量化」の講演 内容をまとめたものである。 